\title{
Adaptability Comparison between the Seedlings of Eucalyptus grandis and Alnus cremastogyne under the Condition of Continuous Drought Stress
}

\author{
Hongling $\mathrm{Hu}$, Hong Chen \& Tingxing $\mathrm{Hu}$ \\ College of Forestry, Sichuan Agricultural University, Yaan 625014, Sichuan, China
}

Jian Zhang (Corresponding author)

Sichuan Provincial Key Laboratory of Forestry Ecological Engineering in Upper Reaches of Yangtze River Yaan 625014, Sichuan, China

Tel: 86-139-0816-0392_E-mail: sicauzhangjian@163.com

$\begin{array}{lc}\text { Received: October 8, } 2011 & \text { Accepted: November 7, } 2011 \quad \text { Online Published: February 2, } 2012 \\ \text { doi:10.5539/jas.v4n4p75 } & \text { URL: http://dx.doi.org/10.5539/jas.v4n4p75 }\end{array}$

This study was founded by National Key Technology R\&D Program of China (No. 2006BAC01A11) and Key Discipline Construction Project in Sichuan Province, China (No. SZD0419).

\begin{abstract}
A pot experiment was carried out to study the growth and physiology responses of Eucalyptus grandis and Alnus cremastogyne seedlings subjected to continuous drought stress. The results were as follows (1) In the case of short treatment time $(0 \sim 6 \mathrm{~d})$, the leaf water status of both species were good, but comparatively higher stomatal conductance(Gs) and transpiration rate(Tr) values of $E$. grandis leaves might lead to higher water consumption. (2) In the more severe drought conditions $(9 \sim 18 \mathrm{~d})$, both species could avoid drought threat by decreasing Gs and Tr. However, A. cremastogyne also took the strategy of defoliation so that the remaining leaves could get adequate water, resulting in its better leaf water status and slighter responses of osmoregulation substances and antioxidant enzymes during $18 \mathrm{~d}$ treatment. (3) A. cremastogyne was more sensitive to drought than E. grandis because of the earlier significant rises but unstable changes of the activity of superoxide dismutase(SOD) and the contents of $\mathrm{H}_{2} \mathrm{O}_{2}$, soluble protein(SP) and proline(Pro) in leaves. (4) In face of drought stress, A. cremastogyne might mainly focus on the drought-avoid strategy to save water and reduce oxidative damage at the cost of growth, however, E. grandis consumed more water for assimilation and production, probably evolved out of a relatively stronger mechanism to face the drought threat such as oxidation damage.

Keywords: Eucalyptus grandis, Alnus cremastogyne, Continuous drought, Physiological response, Adaptive strategy

\section{Introduction}

Water is one of the key factors which affect the growth, distribution and introduction of plants (Jia et al, 2002; Shvaleva et al, 2005). It is well known that about one third of the continent is in arid and semi-arid status (Guo et al, 2003; Luo \& Li, 2005). And more seriously, seasonal or periodic droughts also happened all over the world occasionally for the complexity of the regional geographic and meteorological factors and the impact of global climate change in recent years (Wang et al, 2008; Yao et al, 2009; Yang, 2008). During the dry season (from Jan. to Mar.), as Zhong et al (2001) observed in eucalyptus stands of Leizhou Peninsula, Guangdong, China, soil water content at the depth of $1 \sim 40 \mathrm{~cm}$ was nearly wilting point. If there were not rain for several days, soil water content at $0 \sim 80 \mathrm{~cm}$ dropped to about $30 \%$ of the field capacity. The growth of crops and trees must be affected to some extent in this case and thus selecting drought-resistant tree species and carrying out rational water management become extremely critical.
\end{abstract}

Eucalyptus grandis, with the features of evergreen, strongly positive, fast-growing, good stem form and 
adaptable (Feng \& Zhang, 2005; Ni et al, 2007), has been developed rapidly throughout the world, especially in India, Brazil and China (Feng et al, 2008). Alnus cremastogyne, deciduous, thermophilic, heliophilous, poor soil tolerating, non-leguminosae nitrogen-fixing plant with rhizobium on root (Wang et al, 2001;Liang et al, 2010), has the potential to be very promising broad-leaved tree species for commercial purposes and vegetation restoration in the south of the Yangtze River (Zhu et al, 2004a). Both are widely used, and play important roles in the projects of short-cycle industrial timber bases.

With regard to the physiology and growth response to drought and adaptation strategies of Eucalyptus and Alnus species, there have been numerous reports, such as the response of leaf water status and the morphology of $E$. globulus (Pita \& Pardos, 2001), the osmolytes of E. globulus and E. astringens (Shvaleva et al, 2005; Ardnt et al, 2008), the photosynthetic parameters of E. globulus and E. camaldulensis to water deficit (Gindaba et al, 2004; Zhong et al, 2003), and the influence of drought on the xylem function of A. glutinosa (Hacke \& Sauter, 1996), the water relations, photosynthetic rate and water use efficiency of A. firma and A. formosana (Liang \& Maruyama, 1995; Zhu et al, $2004 \mathrm{a}, \mathrm{b}$ ), etc. These studies tended to merely focus on one side of growth and physiology, and the comparisons were mostly made between clones or congeneric species, but very few integrated comparisons on the drought adaptability, especially between E. grandis and A. cremastogyne, have been reported. Additionally, the analysis and evaluations based on the water status, osmotic adjustment, antioxidant metabolism and photosynthesis under the same experimental condition have been rarely found in publications.

In terms of the experimental designs, the formers often took the approaches which controlled soil moisture level in the series (Pita \& Pardos, 2001; Guo et al, 2003; Zhong et al, 2003; Shariat \& Assareh, 2008), even the method of PEG stress simulation was used (Zhu et al, 2004b). Obviously it was difficult to reflect the response of the trees which suffered from the continuous drought in the field by the studies mentioned above. Therefore, this study, with pot experiment and continuous drought stress for different days, simulated prolonged drought conditions experienced by E.grandis and A. cremastogyne to observe their growth and physiology response, analyzed and compared their drought-resistant (drought-tolerant) characteristics and adaptation mechanisms to provide a theoretical reference for the selection of afforestation tree species and water management in the periodic drought-prone areas.

\section{Materials and Methods}

\subsection{Site Description}

The experiment was conducted at the teaching and research farm of Sichuan Agricultural University, southwest of Sichuan Province, China $\left(29^{\circ} 58^{\prime} 48^{\prime \prime} \mathrm{N}, 102^{\circ} 59^{\prime} 55^{\prime \prime} \mathrm{E}, 600 \mathrm{~m}\right.$ altitude, a. s. 1.).The annual average temperature is $14.1{ }^{\circ} \mathrm{C} \sim 17.9{ }^{\circ} \mathrm{C}, \geq 10{ }^{\circ} \mathrm{C}$ accumulated temperature is $5231{ }^{\circ} \mathrm{C}$, monthly mean maximum temperature $29.9{ }^{\circ} \mathrm{C}$ (Jul.), monthly average minimum temperature $3.7{ }^{\circ} \mathrm{C}$ (Jan.). Average annual sunshine hours $1039.6 \mathrm{~h}$, frost-free period $298 \mathrm{~d}$, the average annual rainfall $1774.3 \mathrm{~mm}$, average air humidity of $79 \%$, subtropical humid monsoon climate with four distinct seasons, rains are more concentrated in the summer, a small temperature difference between day and night, much rain, insufficient light.

\subsection{Soil and Tree Seedlings}

The local common sandy loam, with the field capacity of $25 \%$ (volumetric water content) and the bulk density of $1.32 \mathrm{~g} \cdot \mathrm{cm}^{-3}$, disinfected with carbendazim, thoroughly mixed and then maintained ventilation for $2 \mathrm{~d}$. The tissue culture plantlets of $E$. grandis and the normal seedlings of $A$. cremastogyne were cultivated in 2010 spring and winter, respectively, with the average height of $17.5 \mathrm{~cm}$ and $30.0 \mathrm{~cm}$. Both were planted in the plastic bucket loaded with $15 \mathrm{~kg}$ of soil, 1 seedling per bucket. HH2 soil moisture analyzer (ML2x, GBR) was used to monitor and control the soil water content at about $20 \%$ (about $80 \%$ of field capacity) in the bucket. Adaptive training of young trees were performed for 5 months before treatments.

\subsection{Experimental Treatments}

Uniform seedlings (21 stems for each) of two species were selected on October 9, 2010 and then both divided into 7 groups ( 3 stems for each group). After the last normal watering, $3 \mathrm{~d}$ as a treatment period, stopped watering for each group successively until October 27 , then a drought time series of $0,3,6,9,12,15,18 \mathrm{~d}$ with soil moisture gradient formed, denoted as D0 (CK), D3, D6, D9, D12, D15, D18 (Tab. 1), respectively.

\subsection{Measurement Items and Methods}

In the end of drought stress (October 28, 2010), the soil water contents in all buckets were measured, and leaf samples were taken for the determination of morphological and physiological indicators. 


\subsubsection{Height and Surface Diameter Growth}

Height and diameter increment: the initial value of height $\left(\mathrm{H}_{1}\right)$ and surface diameter $\left(\mathrm{S}_{1}\right)$ were measured at the beginning of drought stress (October 9, 2010), and measured again in the end of drought stress (October 28, 2010), denoted as $\mathrm{H}_{2}$ and $\mathrm{S}_{2}$, respectively. Height increment $\Delta \mathrm{H}=\mathrm{H}_{2}-\mathrm{H}_{1}$, and diameter increment $\Delta \mathrm{S}=\mathrm{S}_{2}-\mathrm{S}_{1}$.

\subsubsection{Water Physiological Traits}

Water physiological indices were determined with the Reference of Whetherley (1950), Gindaba et al (2004). The mature leaves in the same position of upper parts of plants were cut and immediately weighed to get the fresh weight (FW), then soaked in distilled water until no further increase in their weight, which at this time was called saturated weight (TW). After that, took out for natural drying indoors for $24 \mathrm{~h}$ and weighed for the FW ', then water-removed in the oven at $105{ }^{\circ} \mathrm{C}$ for $30 \mathrm{~min}$, finally dried to constant weight (DW) under the conditions of $80{ }^{\circ} \mathrm{C}$. Results of calculations were as follows:

Leaf water content $(\mathrm{LWC})=(\mathrm{FW}-\mathrm{DW}) / \mathrm{FW} \times 100 \%$

Leaf relative water content $($ LRWC $)=($ FW-DW $) /($ TW-DW $) \times 100 \%$

Leaf water retention capacity $(\mathrm{LWRC})=\left[1-\left(\mathrm{TW}-\mathrm{FW}{ }^{\prime}\right) /(\mathrm{TW}-\mathrm{DW})\right] \times 100 \%$

\subsubsection{Photosynthesis and Gas Exchange Parameters}

Using LI-6400 portable photosynthesis meter (LI-COR Inc.USA) to determine the net photosynthetic rate (Pn), stomatal conductance (Gs) and transpiration rate (Tr). Instrument parameters were set as: light intensity 1000 $\mu \mathrm{mol} \cdot \mathrm{m}^{-2} \cdot \mathrm{s}^{-1}, \mathrm{CO}_{2}$ concentration $400 \mu \mathrm{mol} \cdot \mathrm{mol}^{-1}$, temperature $25{ }^{\circ} \mathrm{C}$. Three replications for each treatment, and five readings for each replication. Water use efficiency (WUE) was calculated according to the formula WUE $=\operatorname{Pn} / \operatorname{Tr}($ Penuelas et al (1998)) .

\subsubsection{Indicators Related to Osmotic Adjustment}

Malondialdehyde (MDA) and soluble sugar (SS) determination: with $10 \%$ trichloroacetic acid (TCA) as grinding solution, $0.6 \%$ thiobarbituric acid (TBA) as the chromogenic agent, the extraction was colored in $100{ }^{\circ} \mathrm{C}$ water bath for $15 \mathrm{~min}$; Soluble protein (SP) determination: with $0.05 \mathrm{~mol} / \mathrm{L}$ pH7.0 phosphate buffer as grinding solution, then the supernatant reacted with Coomassie brilliant blue G250 solution. Free proline (Pro) was extracted by $3 \% 5$ - sulfosalicylic acid in boiling water bath for $15 \mathrm{~min}$, colored by ninhydrin reaction in boiling water bath for $30 \mathrm{~min}$, extracted with toluene when cooling naturally, and finally the toluene solution was colorimetric analyzed; The parameters above were all measured by the spectrophotometry suggested by Xiong (2003).

\subsubsection{Indicators Related to Reactive Oxygen Metabolism}

Hydrogen peroxide $\left(\mathrm{H}_{2} \mathrm{O}_{2}\right)$ content was measured with reference to the method suggested by Lin et al (1988) : According to the principle that $\mathrm{H}_{2} \mathrm{O}_{2}$ and titanium ion bind to colored $\left[\mathrm{TiO}\left(\mathrm{H}_{2} \mathrm{O}_{2}\right){ }^{2+}, \mathrm{H}_{2} \mathrm{O}_{2}\right.$ was determined by the colorimetry ; Superoxide dismutase (SOD) activity was determined using the method called NBT photochemical reduction, 50\% activity of SOD photochemical reduced was calculated as a unit $\mathrm{U}$ of activity (Giannopolitis, 1977); Peroxidase (POD) activity was determined by the method of guaiacol (Xiong, 2003), the increment of 0.01 at $A_{470 n m}$ per min was defined as a unit $U$ of activity; Ascorbic acid (AsA) content was determined in the light of Hodges et al (1996). The reaction of AsA and ammonium molybdate in the presence of sulfate and phosphate ions generated a blue complex, then AsA content was determined by the colorimetry.

\subsection{Statistical Analysis}

One-way ANOVA with Fisher's LSD test and Person linear correlation analysis were conducted using SPSS 16.0 (SPSS Inc., USA) statistical analysis software for windows. Mapping was performed using Microsoft Excel 2003. Significant effects were determined at $P<0.05$ for significant difference or $P<0.01$ for extremely significant difference. Mean values in the text were given $\pm 1 \mathrm{SE}$.

\section{Results}

\subsection{Response of Leaf Water Status to Continuous Drought}

The water content of soil used to cultivate the two species both declined with the extension of drought time and showed the trend of "slow - fast - slow", and the water content of soil on which A. cremastogyne seedlings were planted was obviously higher than that of soil planted with E. grandis seedlings, but after $12 \mathrm{~d}$ of drought this difference decreased (Fig. 1 D). The leaf water content (LWC) of E. grandis remained stable during $0 \sim 6 \mathrm{~d}$, while relative water content (LRWC) was significantly reduced after $6 \mathrm{~d}$. With the aggravation of drought stress, both LWC and LRWC declined rapidly, amplitudes were even up to $49.83 \%$ and $61.77 \%$, respectively, when 
drought for $18 \mathrm{~d}$. But the fluctuation of LWC of A. cremastogyne was small (in the range of 5.76\%) during the whole drought period of $18 \mathrm{~d}$, and the drop of LRWC was only $1.40 \% \sim 14.82 \%$ (Fig. $1 \mathrm{~A}, \mathrm{~B}$ ). Correlation analysis showed significant positive correlation between the LWC and soil moisture content, and extremely significant positive correlation between the LRWC and soil moisture content referred to E. grandis. For A. cremastogyne, only LRWC is significantly positive correlated to soil moisture, indicating that the leaf water status of A. cremastogyne is relatively stable in the dry process. From fig. $1 \mathrm{C}$, we can see that the change of leaf water retention capacity (LWRC) of the two species showed the opposite trends, and the LWRC of E. grandis was always clearly higher than that of $A$. cremastogyne.

\subsection{Response of Leaf Osmolytes to Continuous Drought}

In the process of drought stress, free proline (Pro), soluble protein (SP), soluble sugar (SS) and other osmolytes in the plants play important roles in the maintenance of cell turgor and the protection of proteins, enzymes and membranes. The changes of these substances reflect the dehydration tolerance of receptors (Blum, 1996; Li et al, 1996; Smirnoff, 1998). In the first $9 \mathrm{~d}$ of drought, the Pro content in leaves of E. grandis showed slight changes, then remarkably increased, and were approximately 7, 4 and 22 times that of normal water supply conditions when drought stressed for 12,15, $18 \mathrm{~d}$, respectively. Also for the SP content in leaves of $E$. grandis there were no significant differences between D0 and D3 D9, but it increased significantly or extremely significantly with the treatments D12 D18. The response of SS was faster. Under D3, the change of SS was found mild, but enhanced significantly or extremely significantly under D6 $\sim$ D18 (Fig. 2 A, B, C); The Pro content in $A$. cremastogyne significantly increased under treatment $\mathrm{D} 6$, and gradually rose until $\mathrm{D} 12$, then began to decrease but still significantly higher than that of D0. The highest increase was about 3 times that of D0. SP increased first in treatment D3 and D6 and then fell to the lowest in D15. A recovery was seen in D18 but still below that of D0. SS did not change significantly during first $9 \mathrm{~d}$ of drought stress, but remarkably reduced when treated for $12 \mathrm{~d}$. Obviously, A. cremastogyne was more sensitive to drought, and moreover, the response of osmolytes in its leaves was neither strong nor positive compared to that of E. grandis (Fig. 2 A, B, C).

\subsection{Response of Leaf Antioxidant System to Continuous Drought}

Scavenging reactive oxygen species (ROS) depends on the members of the enzymatic defense system (superoxide dismutase (SOD), peroxidase (POD), etc.) and the secondary metabolites ( $\beta$-carotene, ascorbic acid (AsA), etc.). Their contents or activities can describe to some extent the resistance capability of plants to drought (García-Plazaola et al, 1997; Sgherri et al, 2000; Wang et al, 1989). With the increasing threat of drought, the SOD and POD activity of $E$. grandis leaves increased gradually but slightly if the drought time was less than $6 \mathrm{~d}$. After $9 \mathrm{~d}$, they were significantly higher and the trend of both appeared to be flat. The SOD activity and the POD activity were positively and significantly correlated and both increased significantly together with $\mathrm{H}_{2} \mathrm{O}_{2}$; AsA content of the treatment of $18 \mathrm{~d}$ significantly increased, while that of other treatments had no significant difference from D0 or even lower than D0 instead; As for A. cremastogyne, The SOD activity was promoted extremely significantly when treated for $3 \mathrm{~d}$, decreased gradually after that, and began to rebound at $12 \mathrm{~d}$, reached the highest at $18 \mathrm{~d}$. The activity of POD first increased, then decreased with the extension of drought, the peak value appeared at D9, and the values lower than that of D0 revealed after water deficit for 15 18 d. In contrast to SOD activity, AsA content decreased first, increased then and decreased again, showed an obvious fluctuation but was significantly lower than that of D0 under all stress treatments (Fig. 3 A, B, C). This indicated that in face of the threat of drought, both species were able to mobilize internal enzymatic removal system actively to prevent the damage caused by ROS, however, E. grandis could maintain the system at a high level while $A$. cremastogyne could not. AsA of both species played a minor role as antioxidant.

\subsection{Response of Leaf $\mathrm{H}_{2} \mathrm{O}_{2}, \mathrm{MDA}$ to Continuous Drought}

Drought has the potential to induce ROS, such as superoxide anion radical $\left(\mathrm{O}_{2}{ }^{-}\right)$and hydrogen peroxide $\left(\mathrm{H}_{2} \mathrm{O}_{2}\right)$, which implement the function of signal transduction but generate oxidative stress as well when the concentrations of which are high enough (Smirnoff, 1998; Finkel et al, 1998; Li, 2006) and can be diagnosed by malondialdehyde (MDA) and other lipid peroxidation products (Rubio et al, 2002; Chen et al, 2000). It could be seen from Fig. 4 and 5 that $\mathrm{H}_{2} \mathrm{O}_{2}$ in E. grandis leaves increased significantly (except D3), and presented a rising trend with the extension of drought time. Meanwhile, MDA content increased constantly, and significantly positively correlated with $\mathrm{H}_{2} \mathrm{O}_{2}$ content, indicating that $E$. grandis leaves under drought stress were facing more serious threats of ROS and oxidative damage. While the content of $\mathrm{H}_{2} \mathrm{O}_{2}$ in A. cremastogyne leaves showed an apparent fluctuation with the extension of drought time and there was no specific regulation. The content of MDA was not significantly changed during the course of $18 \mathrm{~d}$ of drought, implying that $A$. cremastogyne leaves might suffer less oxidative threat. 


\subsection{Response of Photosynthetic Parameters to Continuous Drought}

Fig. $6 \sim 8$ showed that in a certain range of treatment time $(0 \sim 6 \mathrm{~d})$, the stomatal conductance (Gs) and transpiration rate ( $T r$ ) of E. grandis leaves maintained at a high level, the net photosynthetic rate (Pn) was not significantly reduced either. Nevertheless, the 3 parameters above declined sharply and remained at a very low level probably for the aggravation of water deficit after $9 \mathrm{~d}$ of drought. The Gs, $\mathrm{Tr}, \operatorname{Pn}$ of $A$. cremastogyne leaves increased significantly in D6 and were obviously lower than those of E. grandis during D0 $\sim$ D6, however, the difference of which between $A$. cremastogyne and E. grandis reduced when drought intensified. As to water use efficiency (WUE), E. grandis leaves developed stably in the initial drought (D0 D6), but remarkably increased when drought for $9 \mathrm{~d}$, and declined then. The leaf WUE of $A$. cremastogyne had a similar trend with but higher than that of E. grandis, the maximum of which was seen in D12, since then maintained at a high level (Fig. 9). The correlation analysis indicated that the Pn, Gs, Tr of E. grandis and its soil moisture were all significantly and positively correlated, while there were no significant linear relationships between the 3 parameters of $A$. cremastogyne and its soil moisture.

\subsection{Response of Surface Diameter and Height Growth to Continuous Drought}

Tab. 2 showed that, with the drought time extended, the height growth of E. grandis was gradually inhibited. While for A. cremastogyne, which presented the uptrend first and downtrend then, even was in D6 significantly higher than that of D0, but negative height growth appeared in D15 and D18 due to the tip wilting of the seedling caused by severe drought. In general, the height growth of E. grandis was higher than that of $A$. cremastogyne to a large extent, and in severe drought $(12 \sim 18 \mathrm{~d})$ the fall of growth of $E$. grandis was smaller than that of $A$. cremastogyne. Besides, the increment of surface diameter of $E$. grandis was basically more than that of $A$. cremastogyne during the process of $18 \mathrm{~d}$ drought, and the diameter increment of both species were negative when drought for $18 \mathrm{~d}$ probably for the contraction of the xylem caused by serious water deficit.

\section{Discussion}

The response of plants to drought stress can be three ways -- escape, avoidance and tolerance (Li, 1998; Chaves et al, 2002). Drought escape means that the plant will complete its life history before the advent of drought. Annuals mainly adopt this way, but clearly impossible for A. cremastogyne and E. grandis; Drought avoidance refers to that some plants prevent water loss or enhance water absorption capacity by reducing leaf area index (Gibson et al, 1991; Lauteri et al, 1997), leaf area (Teklehaimanot et al, 1998), forming well-developed palisade tissue (Ma et al, 2002) and thick cuticle (Li, 1998; Luo \& Li, 2005) and changing biomass allocation (Silva et al, 2004), etc. Some plants increase the concentrations of intracellular osmoregulation substances (Delauney \& Verma, 1993) and regulate the activities of antioxidant enzymes (Rubio et al, 2002), etc., to deal with dehydration caused by drought stress and avoid further damage, which is defined as drought tolerance. Plants (even intraspecies) living in different environments for a long time have developed various ways and means to adapt to different conditions (Pita \& Pardos, 2001).

\subsection{Water Consumption and the Strategies for Avoiding Drought of E. grandis and A. cremastogyne}

An et al (1993) found that the vascular area of E. grandis was small, the structure of which was simple and the palisade tissue was thin and loose, therefore the conclusion they reached was that $E$. grandis could grow better in the soil with good moisture condition. By contrast, well-developed palisade tissue maybe was one of the characteristics of drought resistance of $A$. cremastogyne as Liang et al (2010) reported. However, the results of this study supported the point that leaves of $E$. grandis possessed stronger anti-dehydration than those of $A$. cremastogyne in terms of the water retention capacity, which was in accord with the reports on $E$. grandis given by Clarke \& Romagosa (1989) and Sun et al (2009). Both species decreased their stomatal conductance to reduce transpiration when aridity reached a certain level. The reason might be that the stress induced the synthesis of a large number of abscisic acid(ABA) in the root, which was transported to the upper parts of aboveground, thus led to stomatal closure ( $\mathrm{Li}$ et al, 2004). Compared with A. cremastogyne, the stomatal conductance and transpiration of $E$. grandis leaves were obviously higher under the condition of normal water supply or at the beginning of drought, and the leaf water content dropped more rapidly with the decline of soil moisture, indicating a larger amount of water consumption. This might be related to the different strategies the two species used to avoid drought. Li (1998) and Li \& Zhu (2006) have reported that in the dry season or under drought stress plants decreased or prevented the water loss by leaf defoliation, wilting, curling or producing smaller blades. In fact, Acute defoliation was observed at the lower and middle part of the plant in the process of drought to A. cremastogyne, while E. grandis rarely defoliated even completely withered in the later period of drought. This was similar to the result obtained by Gindaba et al (2004) that three deciduous tree species retained only the latest germinated leaves, thus the water status of which was better than that of two Eucalyptus under 
drought stress. As a result, comparatively larger total leaf area and total transpiration but easier water deficit happened to E. grandis.

\subsection{The Physiological-biochemical Regulation and Drought-tolerant Strategy of E. grandis and A. cremastogyne}

It was inevitable that leaves of $E$. grandis suffered dehydration during the drought because of its non-defoliation strategy coupled with strong transpiration in the early stage of drought, so the drought-tolerant mechanisms had to be enabled. On the one hand, SOD, POD activity rose collaboratively to cope with the accumulation of drought-induced ROS, such as $\mathrm{O}_{2}{ }^{-}$and $\mathrm{H}_{2} \mathrm{O}_{2}$, so as to prevent oxidative damage, whereas such ability was limited. In the short term drought $(0 \sim 6 \mathrm{~d}$, the drop of soil moisture was less than $47.77 \%)$, SOD and POD were able to keep MDA at the level of CK (D0). Yet it was difficult for them to prevent obvious injury from lipid peroxidation if the drought time prolonged. On the other hand, the proportion of various endocyte (Pro, soluble protein, soluble sugar) increased in the cytosol (especially during $9 \sim 18 \mathrm{~d}$ when the dramatic decline of soil water content happened ) to maintain the cell turgor, to strengthen water absorption and transport capacity (Tyree \& Hammel, 1972 ). They were even believed to help remove ROS and stabilize membrane and protein structure (Smirnoff, 1998;Rathinasabapathi, 2000; Shvaleva et al, 2005). While for A. cremastogyne, the leaves remained on the plant could get ampler water in the process of drought for $18 \mathrm{~d}$ because of its lower transpiration rate and defoliation strategy, therefore the osmoregulation and antioxidative metabolism were not so strong as those of $E$. grandis, the change of MDA content was not significant, implying that the oxidation threat was not serious to $A$. cremastogyne. However, the reactions of osmolytes and antioxidants were more sensitive (e.g. $\mathrm{H}_{2} \mathrm{O}_{2}$, SOD, Pro and soluble protein of $A$. cremastogyne were already significant changed in D3). When the stress time reached $15 \sim 18 \mathrm{~d}$, SOD, soluble sugar and soluble protein in A. cremastogyne leaves rebounded more or less, demonstrating that obvious threat of dehydration and peroxidation might also happen to it if the treatment time exceeded $18 \mathrm{~d}$.

\subsection{Productivity of E. grandis and A. cremastogyne under the Continuous Drought Condition}

Increase of WUE of plants was often found under drought stress, but it was considered to be at the cost of slower growth, as Heitholt (1989) believed. Ma et al (2002) found that Eucalyptus species consumed more water to keep their higher assimilation capacity in order to adapt to hot-dry environment, while the assimilation of several species of Acacia was lower together with the lesser consumption of water. E. grandis was likely to lay particular emphasis on photosynthetic production rather than water conservation in the balance of the two, thus it did not take measures of defoliation (Cowan, 1978).

Although the WUE (and the Pn in the later stage of drought stress) of a single leaf of A. cremastogyne was higher, it was evident that much smaller total leaf area might result in lower WUE at yield level compared with $E$. grandis (Wang \& Liu, 2000). This was the reason why A. cremastogyne suffered greater inhibition in growth. When drought for $6 \mathrm{~d}$, Gs and Tr of $A$. cremastogyne significantly increased probably on account of the optimal soil water content $(17.72 \%)$ for the activity of the rhizobia, while too wet or too dry soil were not conducive to their growth and breeding ( $\mathrm{Wu}, 1992)$.

\section{Conclusion}

In summary, under drought condition, E. grandis mainly took the measure of tolerance (increasing the contents of osmolytes and the activities of antioxidative enzymes) to ensure the absorption and the transport of water and prevent further damage caused by dehydration. It also took the strategy of drought avoidance by maintaining a high water holding capacity and reducing leaf stomatal conductance to reduce water loss. A. cremastogyne mainly adopted the drought avoidance strategy (defoliation, decrease of stomatal conductance) to reduce water consumption, whereas efforts on drought tolerance were hardly made. E. grandis retained most of its leaves to maintain the accumulation of photosynthetic products in face of water deficit, as a result, water consumption was relatively higher. So $E$. grandis might suffer great injury more easily with prolonged drought time. Thus in forest management, to ensure that 1 a seedlings of both species grow well, persistent drought of no more than $9 \mathrm{~d}$ was recommended to avoid too low soil moisture. Additionally, in the areas where annual rainfall is low and the seasonal distribution of which is uneven, such as the central and east regions of Sichuan Basin, one should be cautious to develop E. grandis, because the continuous drought often persists tens of days.

The death points of drought on these two species were not discovered in this study, their restorability after rewatering were not observed either. And whether or not the drought resistance would enhance if the age of plant increases? All these above remain to be more comprehensive in-depth studied so as to evaluate and compare their drought adaptabilities scientifically. 


\section{Acknowledgements}

This study was founded by National Key Technology R\&D Program of China (No. 2006BAC01A11) and Key Discipline Construction Project in Sichuan Province, China (No. SZD0419).

\section{References}

An, P, Hong, C F, \& Cai, Z K. (1993). An anatomical analysis of leaves of 13 Eucalyptus species introduced in Fujian Province. Journal of Fujian Forestry Science and Technology, 20, 8-15.

Arndt, S K, Livesley, S J, Merchant, A, Bleby, T M, \& Grierson, P F. (2008). Quercitol and osmotic adaptation of field-grown Eucalyptus under seasonal drought stress. Plant, Cell and Evironment, 31, 915-924. http://dx.doi.org/10.1111/j.1365-3040.2008.01803.x

Blum, A. (1996). Crop responses to drought and the interpretation of adaptation. Plant Growth Regulation, 20, 135-148. http://dx.doi.org/10.1007/BF00024010

Chaves, M M, Pereira, J S, Maroco, J P, Rodrigues, M L, Ricardo, C P P, Osório, M L, Carvalho, I, Faria, T, \& Pinheiro, C. (2002). How plants cope with water stress in the field. Photosynthesis and growth. Annals of Botany, 89, 907-916. http://dx.doi.org/10.1093/aob/mcf105

Chen, H B, Guo, J H, Wang, J S, Jing, R L, Chang, X P, \& Cao, K L. (2000). Relationship between drought resistance and the changes of biochemical indexes from wheat buds and seedlings with water stress. Journal of Shanxi Agricultural University, 20, 129-131.

Clarke, J M, Romagosa, I, Jana, S, Srivastava, J P, \& McCaig, T N. (1989). Relationship of excised-leaf water loss rate and yield of durum wheat in diverse environments. Canadian Journal of Plant Science, 69, 1075-1081. http://dx.doi.org/10.4141/cjps89-130

Cowan, I R. (1978). Stomatal behavior and environment. Advances in Botanical Research, 4, 217-228. http://dx.doi.org/10.1016/S0065-2296(08)60370-5

Delauney, A J, \& Verma, D P S. (1993). Proline biosynthesis and osmoregulation in plants. The Plant Journal, 4, 215-223. http://dx.doi.org/10.1046/j.1365-313x.1993.04020215.x

Feng, J, \& Zhang, J. (2005). Ecological distribution patterns of soil microbes under artificial Eucalyptus grandis stand. Chinese Journal of Applied Ecology, 16, 1422-1426.

Feng, L Z, Liu, Y B, Guo, S Z, Huang, R H, \& Guo, W S. (2008). Relationship between the leaf anatomical characteristics of Eucalyptus and its resistance to dieback. Journal of Chinese Electron Microscopy Society, 27, 229-234.

Finkel, T. (1998). Oxygen radicals and signaling. Current Opinion in Cell Biology, 10, 248-253. http://dx.doi.org/10.1016/S0955-0674(98)80147-6

García-Plazaola, J I, Faria, T, Abadía, J, Abadía, A, Chaves, M M, \& Pereira, J S. (1997). Seasonal changes in xanthophyll composition and photosynthesis of cork oak (Quercus suber L.) leaves under mediterranean climate. Journal of Experimental Botany, 48, 1667-1674. http://dx.doi.org/10.1093/jxb/48.9.1667

Giannopolitis, C N, \& Roes, S K. (1977). Superoxide dismutases.I. Occurrence in higher plants. Plant Physiology, 59, 309-314. http://dx.doi.org/10.1104/pp.59.2.309

Gibson, A, Hubick, K T, \& Bachelard, E P. (1991). Effects of abscisic acid on morphological and physiological responses to water stress in Eucalyptus camaldulensis seedlings. Australian Journal of Plant Physiology, 18, 153-163. http://dx.doi.org/10.1071/pp9910153

Gindaba, J, Rozanov, A, \& Negash, L. (2004). Response of seedlings of two Eucalyptus and three deciduous tree species from Ethiopia to severe water stress. Forest Ecology and Management, 201, 119-129. http://dx.doi.org/10.1016/j.foreco.2004.07.009

Guo, W H, Li, B, Huang, Y M, Zhao, H X, \& Zhang, X S. (2003). Effects of different water stresses on eco-physiological characteristics of Hippophae rhamnoides seedlings. Acta Botanica Sinica, 45(10), 1238-1244.

Hacke, U, \& Sauter, J J. (1996). Drought-induced xylem dysfunction in petioles, branches, and root of Populus balsamifera L. and Alnus glutinosa (L.) Gaertn. Plant Physiology, 111, 413-417. http://dx.doi.org/10.1104/pp.111.2.413

Heitholt, J J. (1989). Water use efficiency and dry matter distribution in nitrogen- and water-stressed winter wheat. Agronomy Journal, 81, 464-469. 
Hodges, D M, Andrews, C J, Johnson, D A, \& Hamilton, R L. (1996). Antioxidant compound responses to chilling stress in differentially sensitive inbred maize lines. Physiologia Plantarum, 98, 685-692. http://dx.doi.org/10.1034/j.1399-3054.1996.980402.x

Jia, W S, Xing, Y, Lu, C M, \& Zhang, J H. (2002). Signal transduction from water stress perception to ABA accumulation. Acta Botanica Sinica, 44, 1135-1141.

Lauteri, M, Scartazza, A, Guido, M C, \& Brugnoli, E. (1997). Genetic variation in photosynthetic capacity, carbon isotope discrimination and mesophyll conductance in provenances of Castanea sativa adapted to different environments. Functional Ecology, 11, 675-683. http://dx.doi.org/10.1046/j.1365-2435.1997.00140.x

Li, C Y. (1998). Advances in research on drought resistance of Eucalyptus. World Forestry Research, 11, $22-27$.

Li, C Y, Yin, C Y, \& Liu, S R. (2004). Different responses of two contrasting Populus davidiana populations to exogenous abscisic acid application. Environmental and Experimental Botany, 51, 237-246. http://dx.doi.org/10.1016/j.envexpbot.2003.11.001

Li, H S. (2006). Modern plant physiology(2nd ed.). Beijing: Higher Education Press, pp339-341.

Li, J Y, \& Zhu, Y. (2006). Effect of drought stress on the characteristics of water consumption of greening tree species in Beijing. Journal of Beijing Forestry University, 28(supp.): 32-37.

Li, W L, Berlyn, G P, \& Ashton, P M S. (1996). Polyploids and their structural and physiological characteristics relative to water deficit in Betula papyrifera(Betulaceae). American Journal of Botany, 83, 15-20. http://dx.doi.org/10.2307/2445949

Liang, N S, \& Maruyama, K. (1995). Interactive effects of $\mathrm{CO}_{2}$ enrichment and drought stress on gas exchange and water-use efficiency in Alnus firma. Environmental and Experimental Botany, 35, 353-361. http://dx.doi.org/10.1016/0098-8472(95)00009-8

Liang, W B, Li, Z H, Xu, Z K, Xiao, X C, \& Zhang, D L. (2010). A study of leaf tissue characteristic and drought resistance of Alnus cremastogyne. Journal of Central South University of Forestry \& Technology, 30, 16-22.

Lin, Z F, Li, S S, Lin, G Z, \& Guo, J Y. (1988). The accumulation of hydrogen peroxide in senescing leaves and chloroplasts in relation to lipid peroxidation. Acta Phytophysiologica Sinica, 14, 16-22.

Luo, Q H, \& Li, Z J. (2005). Study achievements of water physiological ecology and drought-resistance of trees. Journal of Tarim University, 17, 29-33.

Ma, H C, McConchie, J A, \& Chen, D Q. (2002). The drought resistance of Acacia and Eucalyptus in Yuanmou dry-hot valley Yunnan Province. Forest Research, 15, 101-104.

Ni, B, Zhang, J, Feng, M S, \& Liu, Y. (2007). Study on the rhizosphere soil enzyme activities in Eucalyptus grandis plantation ecosystem. Journal of Sichuan Agricultural University, 25, 311-315.

Penuelas, J, Filella, I, Llusia, J, Siscart, D, \& Pinol, J. (1998). Comparative field study of spring and summer leaf gas exchange and photobiology of the mediterranean trees Quercus ilex and Phillyrea latifolia. Journal of Experiment Botany, 49, 229-238. http://dx.doi.org/10.1093/jxb/49.319.229

Pita, P, \& Pardos, J A. (2001). Growth, leaf morphology, water use and tissue water relations of Eucalyptus globulus clones in response to water deficit. Tree Physiology, 21, 599-607. http://dx.doi.org/10.1093/treephys/21.9.599

Rathinasabapathi, B. (2000). Metabolic engineering for stress tolerance: installing osmoprotectant synthesis pathways. Annals of Botany, 86, 709-716. http://dx.doi.org/10.1006/anbo.2000.1254

Rubio, M C, González, E M, Minchin, F R, Webb, K J, Arrese-Igor, C, Ramos, J, \& Becana, M. (2002). Effects of water stress on antioxidant enzymes of leaves and nodules of transgenic alfalfa overexpressing superoxide dismutases. Physiologia Plantarum, 115, 531-540. http://dx.doi.org/10.1034/j.1399-3054.2002.1150407.x

Sgherri, C L M, Maffei, M, \& Navari-Izzo, F. (2000). Antioxidative enzymes in wheat subjected to increasing water deficit and rewatering. Journal of Plant Physiology, 157, 273-279.

Shariat, A, \& Assareh, M H. (2008). Effects of drought stress on pigments, prolin, soluble sugar and growth parameters on four Eucalyptus species. Pajouhesh \& Sazandegi, 21, 139-148.

Shvaleva, A L, Silva, F C E, Breia, E, Jouve, L, Hausman, J F, Almeida, M H, Maroco, J P, Rodrigues, M L, Pereira, J S, \& Chaves, M M. (2005). Metabolic responses to water deficit in two Eucalyptus globulus clones with contrasting drought sensitivity. Tree Physiology, 26, 239-248. http://dx.doi.org/10.1093/treephys/26.2.239 
Silva, F C E, Shvaleva, A, Maroco, J P, Almeida, M H, Chaves, M M, \& Pereira, J S. (2004). Responses to water stress in two Eucalyptus globulus clones differing in drought tolerance. Tree Physiology, 24, 1165-1172. http://dx.doi.org/10.1093/treephys/24.10.1165

Smirnoff, N. (1998). Plant resistance to environmental stress. Current Opinion in Biotechnology, 9, $214-219$. http://dx.doi.org/10.1016/S0958-1669(98)80118-3

Sun, Y Y, Li, K, Cui, Y Z, \& Luo, C W. (2009). Drought-resistant physiological characteristics of Eucalyptus maculate seedlings in dry-hot valley. Journal of Northeast Forestry University, 37, 1-2.

Teklehaimanot, Z, \& Lanek, J, Tomlinson, H F. (1998). Provenance variation in morphology and leaflet anatomy of parkia biglobosa and its relation to drought tolerance. Trees structure and Function, 13, 96-102. http://dx.doi.org/10.1007/PL00009742

Tyree, M T, \& Hammel, H T. (1972). The measurement of the turgor pressure and the water relations of palnts by the pressure-bomb technique. Journal of Experimental Botany, 23, $267-282$. http://dx.doi.org/10.1093/jxb/23.1.267

Wang, H, Li, X B, Li, X, \& Wang, D D. (2008). Grassland response to drought in northern China. Acta Ecologica Sinica, 28, 172-182.

Wang, H X, \& Liu, C M. (2000). Advances in crop water use efficiency research. Advances in Water Science, 11, 99-104.

Wang, J H, Gu, W C, Xia, L F, Li, B, \& Guo, W Y. (2001). Genetic variation and selection of wood property of Alnus cremastogyne provenance and family. Forest Research, 14, 362-368.

Wang, Z Y, Guo, A G, \& Luo, S P. (1989). Effect of water stress upon SOD and POD activity and isoenzyme of corn. Acta Universitatis Septentrionali Occidentali Agriculturae, 17, 45-49.

Weatherley, P E. (1950). Studies in the water relations of cotton plants. I . The field measurement of water deficits in leaves. New Phytologist, 49, 81-87. http://dx.doi.org/10.1111/j.1469-8137.1950.tb05146.x

Wu, X L. (1992). The influence of high temperature and drought on the growth, nodulation and nitrogen-fixation of Alnus cremastogyne in different kinds of soils. Forest Research, 5, 225-230.

Xiong, Q E. (2003). Plant physiology labs. Chengdu: Sichuan Science and Technology Press.

Yang, W X. (2008). China's arid regions in the global change: response and trend. Scientia Silvae Sinicae, 44, 124-130.

Yao, Y B, Dong, A X, Zhang, X Y, \& Wang, Y R. (2009). Comparison research on characteristics of regional drought in summer over China. Agricultural Research in the Arid Areas, 27, 248-253, 264.

Zhong, J H, Liao, G R, Guo, Q R, Liao, X R, Li, S Y, \& Lan, P L. (2003). Physio-ecological characteristics of young Eucalyptus under different soil water conditions. Journal of Soil and Water Conservation, 17, $126-128$.

Zhong, J H, Liao, G R, Li, S Y, Guo, Q R, Tan, J, Lan, P L, \& Liao, X R. (2001). Moisture status of latosol under Eucalyptus in Leizhou Peninsula. Bulletin of Soil and Water Conservation, 21, 43-45.

Zhu, W Z, Wang, J X, \& Xue, J H. (2004a). Water physiological characteristics of introduced Alnus formosana. Journal of Wuhan Botanical Research, 22, 539-545.

Zhu, W Z, Xue, J H, \& Wang, J X. (2004b). Effects of water stress on net photosynthesis of Alnus formosana provenances and its drought tolerance. Journal of Soil and Water Conservation, 18, 170-173, 181.

Table 1. The experiment design

\begin{tabular}{|c|c|c|c|c|c|c|c|}
\hline \multirow{2}{*}{ Drought treatment } & \multicolumn{7}{|c|}{ (time) } \\
\cline { 2 - 8 } & 10.09 & 10.12 & 10.15 & 10.18 & 10.21 & 10.24 & 10.27 \\
\hline D0 & + & + & + & + & + & + & + \\
\hline D3 & + & + & + & + & + & + & - \\
\hline D6 & + & + & + & + & + & - & - \\
\hline D9 & + & + & + & + & - & - & - \\
\hline D12 & + & + & + & - & - & - & - \\
\hline D15 & + & + & - & - & - & - & - \\
\hline D18 & + & - & - & - & - & - & - \\
\hline
\end{tabular}

Note: "+" denotes that watering was implemented on the day, "-" denotes that watering was not implemented. 
Table 2. Height and surface diameter growth of E. grandis and A. cremastogyne seedlings under the condition of continuous drought stress

\begin{tabular}{|c|c|c|c|c|}
\hline \multirow{2}{*}{$\begin{array}{l}\text { Water } \\
\text { treatment }\end{array}$} & \multicolumn{2}{|c|}{ E. grandis } & \multicolumn{2}{|c|}{ A. cremastogyne } \\
\hline & $\begin{array}{l}\text { Growth of } \\
\text { height }(\mathrm{cm})\end{array}$ & $\begin{array}{l}\text { Growth of surface } \\
\text { diameter(mm) }\end{array}$ & $\begin{array}{l}\text { Growth of } \\
\text { height }(\mathrm{cm})\end{array}$ & $\begin{array}{c}\text { Growth of surface } \\
\text { diameter(mm) }\end{array}$ \\
\hline D0 & $7.67 \pm 1.34 \mathrm{Aa}$ & $6.28 \pm 2.30 \mathrm{Aa}$ & $2.10 \pm 0.14 \mathrm{ABCb}$ & $4.25 \pm 1.37 \mathrm{Aa}$ \\
\hline D3 & $7.10 \pm 2.40 \mathrm{Aab}$ & $3.74 \pm 1.23 \mathrm{Aa}$ & $2.40 \pm 0.28 \mathrm{ABab}$ & $3.67 \pm 1.73 \mathrm{Aab}$ \\
\hline D6 & $5.77 \pm 1.82 \mathrm{ABab}$ & $6.84 \pm 0.24 \mathrm{Aa}$ & $3.70 \pm 1.98 \mathrm{Aa}$ & $2.06 \pm 0.67 \mathrm{Aab}$ \\
\hline D9 & $\begin{array}{c}3.90 \pm 0.85 \\
\text { ABCbcd }\end{array}$ & $4.90 \pm 2.14 \mathrm{Aa}$ & $2.37 \pm 2.37 \mathrm{ABab}$ & $3.23 \pm 1.78 \mathrm{Aab}$ \\
\hline D12 & $\begin{array}{c}4.70 \pm 1.98 \\
\mathrm{ABCabc}\end{array}$ & $2.71 \pm 1.32 \mathrm{ABa}$ & $1.00 \pm 0.99 \mathrm{ABb}$ & $1.53 \pm 0.55 \mathrm{ABb}$ \\
\hline D15 & $2.03 \pm 1.53 \mathrm{BCcd}$ & $1.23 \pm 0.18 \mathrm{Cb}$ & $-3.90 \pm 0.42 \mathrm{Cc}$ & $2.31 \pm 0.27 \mathrm{Aab}$ \\
\hline D18 & $0.70 \pm 0.57 \mathrm{Cd}$ & $-0.98 \pm 1.17 \mathrm{BCb}$ & $\begin{array}{c}-2.80 \pm 0.42 \\
\mathrm{BCc} \\
\end{array}$ & $-1.37 \pm 1.15 \mathrm{Bc}$ \\
\hline
\end{tabular}
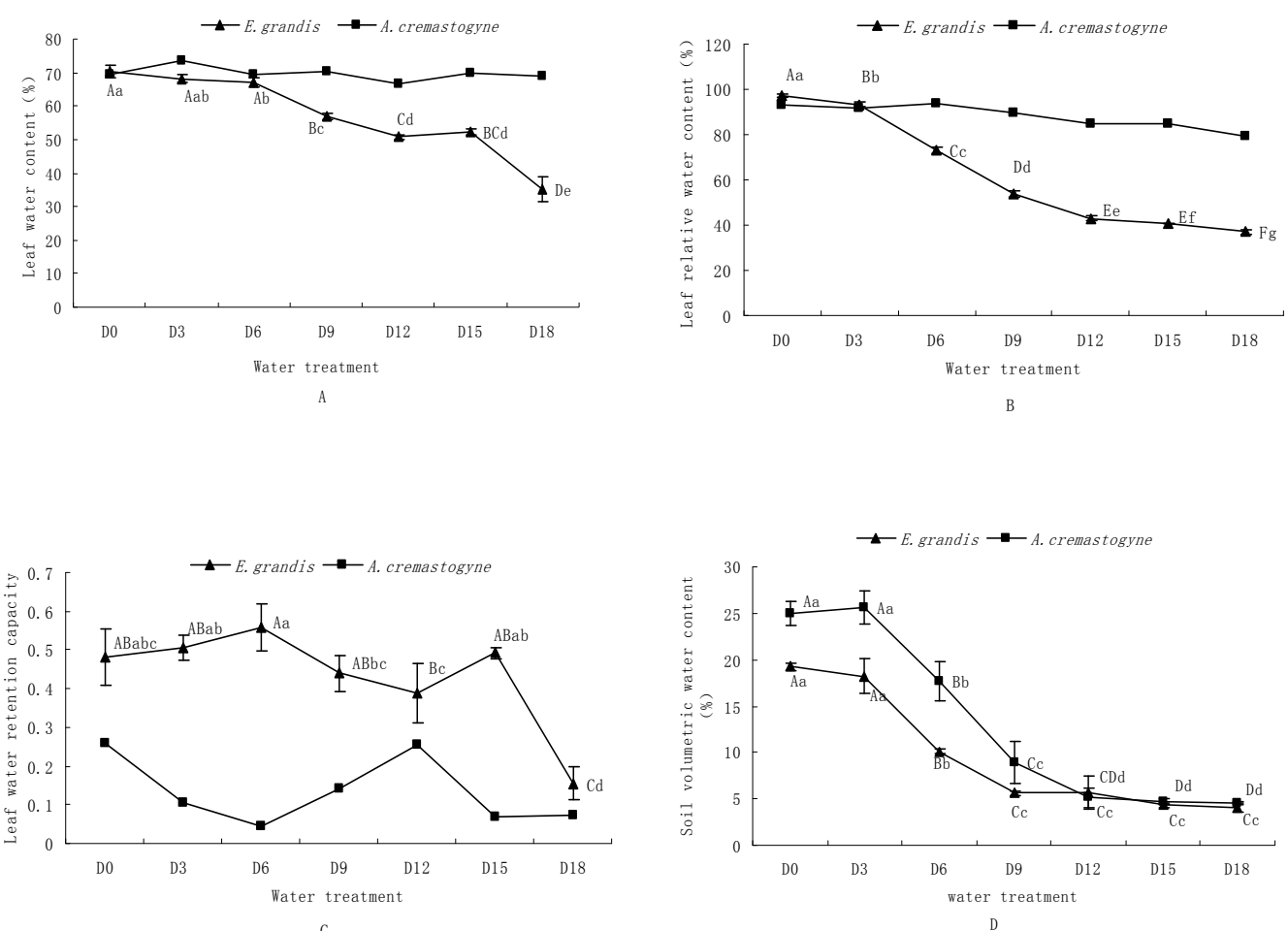

Figure 1. The change of soil water content and leaf water indices of E. grandis and A. cremastogyne under the condition of continuous drought stress

Note: the same line meant the significance was at the level of 0.01 and 0.05 respectively within mean values. The same as below. 

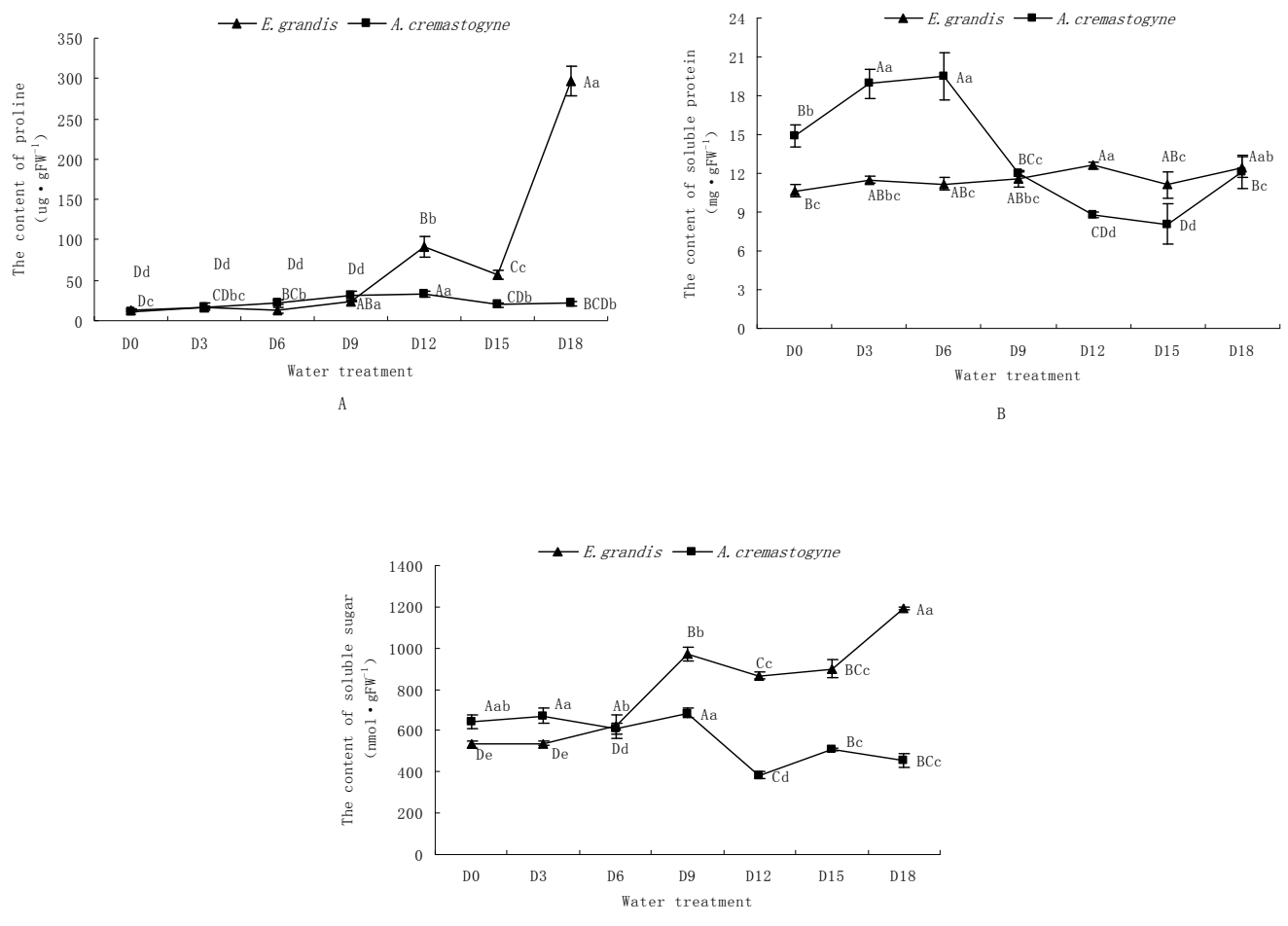

Figure 2. The response of three osmolytes of $E$. grandis and A. cremastogyne to continuous drought stress
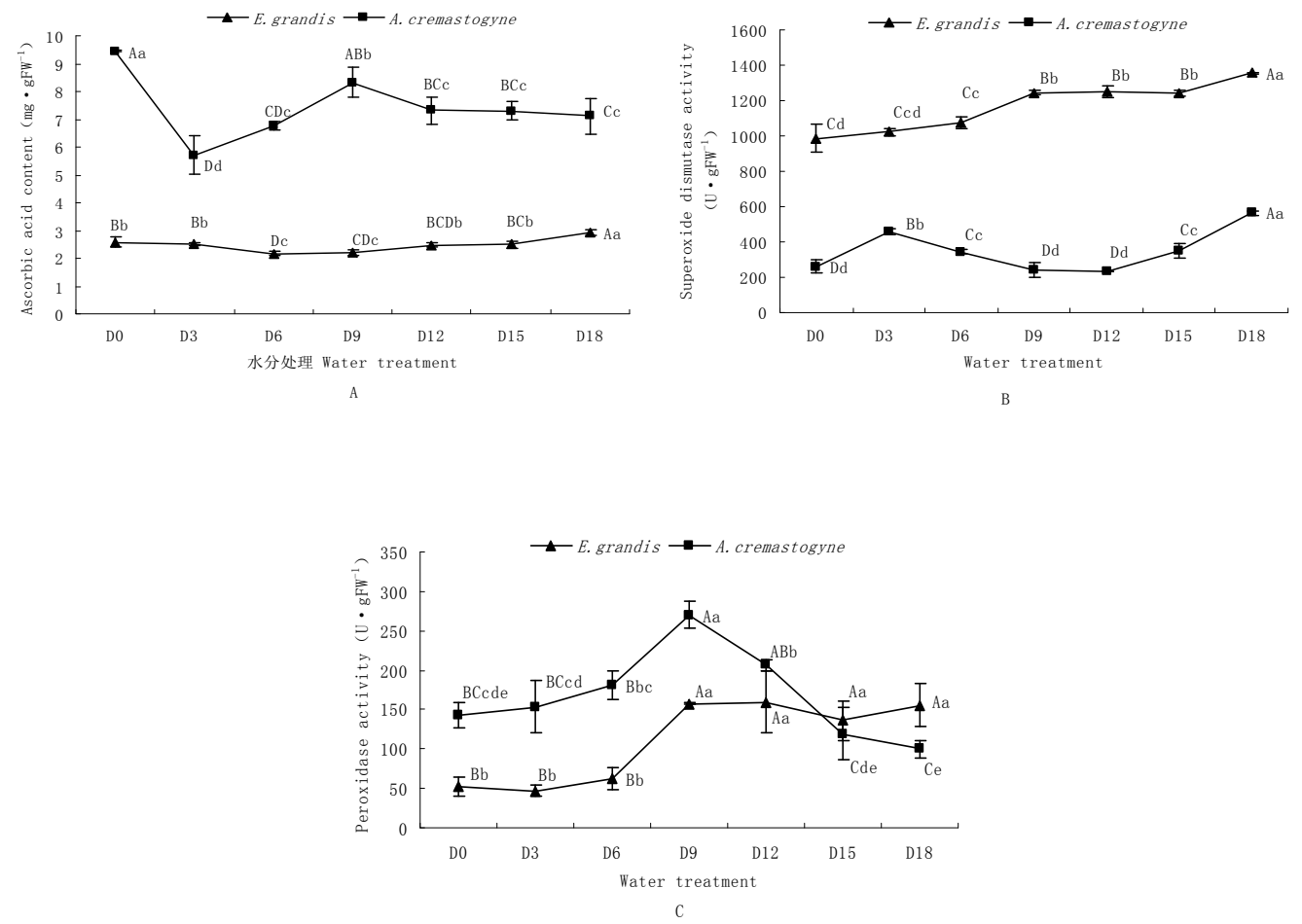

Figure 3. The effect of continuous drought stress on antioxidant system of E. grandis and A. cremastogyne 


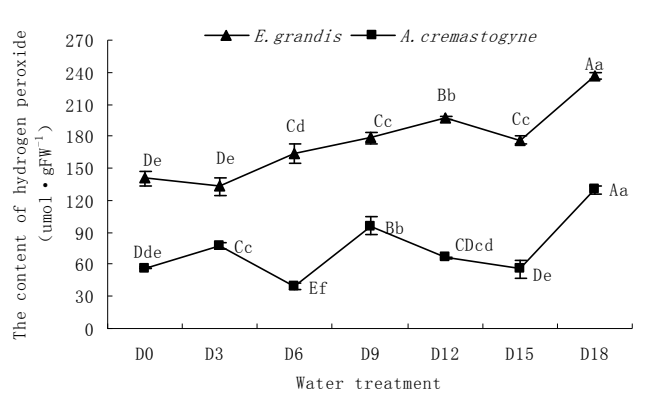

Figure 4. The response of $\mathrm{H}_{2} \mathrm{O}_{2}$ of E. grandis and $A$. cremastogyne leaves to continuous drought stress

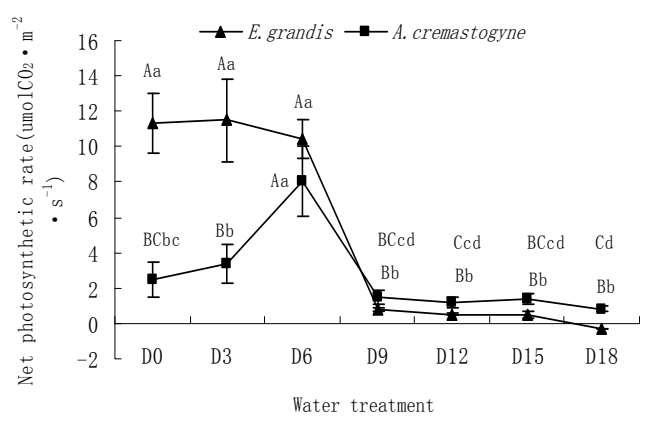

Figure 6. The response of net photosynthetic rate of E. grandis and A. cremastogyne to continuous drought stress

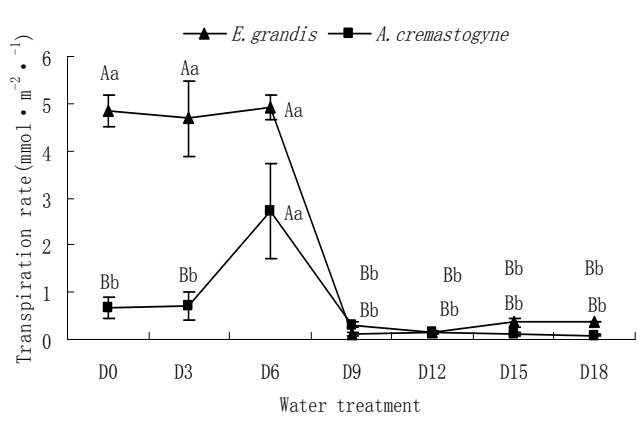

Figure 8. The response of transpiration rate of E. grandis and $A$. cremastogyne to continuous drought stress

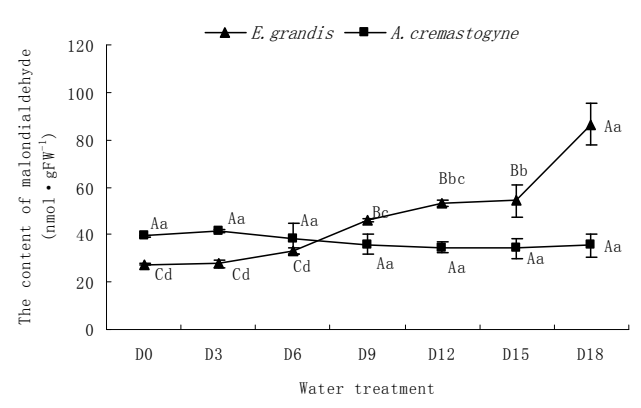

Figure 5. The response of MDA of E. grandis and $A$. cremastogyne leaves to continuous drought stress

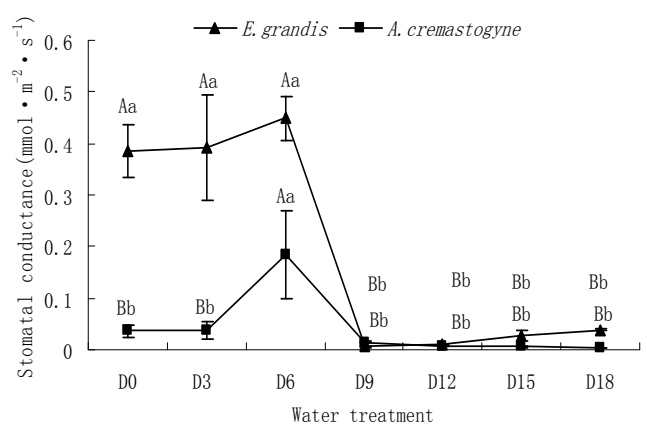

Figure 7. The response of Stomatal conductance of E. grandis and A. cremastogyne to continuous drought stress

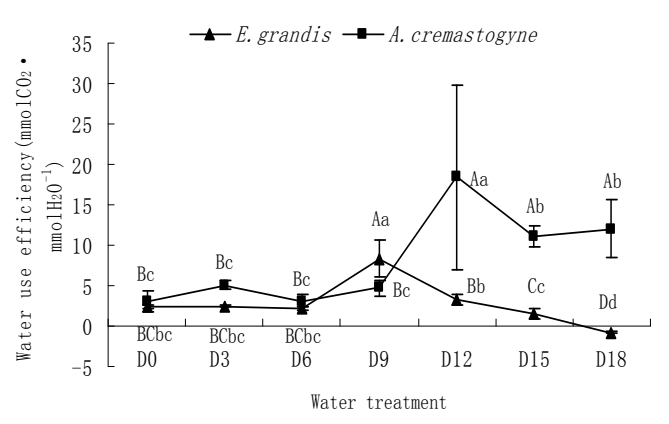

Figure 9. The response of water use efficiency of E. grandis and A. cremastogyne to continuous drought stress 